\title{
PELVIC FLOOR MUSCLE BEHAVIOR DURING VALSALVA LEAK POINT PRESSURE MEASUREMENT IN MALES AND FEMALES AFFECTED BY STRESS URINARY INCONTINENCE
}

\author{
ANTONELLA GIANNANTONI, SAVINO M. DI STASI, ANTONIO CUCCHI, ETTORE MEARINI, \\ VITTORIO BINI AND MASSIMO PORENA
}

From the Departments of Urology, University of Perugia, Perugia, "Tor Vergata" University of Rome, Rome, and Policlinico S. Matteo, Pavia, Italy

\section{ABSTRACT}

Purpose: We evaluated pelvic floor muscle (PFM) behavior during Valsalva leak point pressure (VLPP) measurement in males and females affected by stress urinary incontinence and investigated whether VLPP results are influenced by PFM contraction.

Materials and Methods: A total of 25 females and 14 males underwent surface electromyographic (EMG) recording of PFM activity while performing VLPP. We investigated 2 conditions, VLPP during spontaneous strain (test A), and with simultaneous relaxation of the pelvic floor (test $\mathrm{B}$ ). We analyzed average EMG activity $(\mu \mathrm{V})$ at rest and during VLPP in tests A and B, the increasing EMG activity during tests A and B (the difference between average EMG activity during tests $\mathrm{A}$ and $\mathrm{B}$ and at rest), and the mean duration (seconds) of EMG activity during tests $\mathrm{A}$ and $\mathrm{B}$.

Results: We detected a significant increase in EMG activity during tests A and B as compared to activity at rest $(\mathrm{p}<0.0001)$. Increasing EMG activity during test B was significantly reduced in females $(\mathrm{p}<0.05)$ but not in males. During test A patients reporting urinary incontinence showed a significantly lower EMG activity than that of continent patients $(p<0.05)$. A significant reduction in maximum abdominal pressure was detected in test $\mathrm{B}$ compared to test $\mathrm{A}$, but there was no difference in VLPP values between tests A and B.

Conclusions: PFM activity significantly increases during VLPP measurement. Eliminating muscular contraction of the pelvic floor does not significantly alter VLPP results.

KEY WoRDS: pelvic floor, muscles; urinary incontinence, stress

Since its introduction in $1993^{1}$ the Valsalva maneuver has been incorporated into the routine evaluation of stress urinary incontinence (SUI). ${ }^{2}$ Assessment of intrinsic sphincter deficiency in patients with a low Valsalva leak point pressure (VLPP) and urethral hypermobility in those with a high VLPP assists in the selection of appropriate treatment. ${ }^{1}$ Although technically simple, measurements of VLPP require some expertise and there are several pitfalls. ${ }^{3}$ It has been assumed that patients with intrinsic sphincter deficiency may voluntarily contract the external urethral sphincter (EUS) during the test thereby increasing the leak point pressure, ${ }^{3}$ and also the precise role of the pelvic floor muscles (PFM) during VLPP measurement is not well known. In the last 9 years more than 50 papers have reported results of clinical studies, data on reproducibility and standardization of VLPP measurements, but only 2 studies described data involving PFM behavior during the test. ${ }^{4,5}$ They reported that the intra-abdominal pressure causing SUI was higher during coughing than during Valsalva and attributed this finding to a simultaneous reflex contraction of EUS, which may be present with a sudden strain (cough) but not with a slow sustained strain (Valsalva). ${ }^{6}$ This report indicates that coughing induces an augmented guarding reflex to prevent unwanted urine loss. ${ }^{7}$ We investigated the behavior of pelvic floor muscles during detection of VLPP in patients affected by SUI, and discerned whether VLPP is influenced by voluntary control of the external sphincter and pelvic floor muscles during the test.

Accepted for publication February 21, 2003.

\section{PATIENTS AND METHODS}

Inclusion criteria. We prospectively included 39 patients in the study, all of whom were informed about the scientific nature of the investigations and provided written informed consent. Enrolled patients complained of SUI with positive stress test and with urodynamic stress incontinence. ${ }^{8}$ They did not present with lower urinary tract symptoms usually related to detrusor overactivity (urgency and urge incontinence) and there was no evidence of detrusor overactivity on filling cystometry. ${ }^{8}$ Patients with a diagnosis of neurogenic disease were excluded from the study, as were women with major urogenital prolapse (grades 3 and 4) which may dissipate the effect of abdominal pressure on the urethra and mask stress incontinence. ${ }^{9} \mathrm{~A}$ history was obtained followed by physical examination, urodynamics, cough leak point pressure (CLPP) and VLPP evaluation with simultaneous recording of the electromyographic (EMG) activity of pelvic floor muscles. Cystourethrography was obtained in all female patients to detect the position of the bladder neck at rest and during stress; the types of SUI were defined using the classification by Blaivas and Olsson. ${ }^{10}$

Urodynamics. Urodynamic assessment followed International Continence Society standards ${ }^{11}$ and involved water cystometry with $37 \mathrm{C}$ normal saline solution at a filling rate of $50 \mathrm{ml}$ per minute. A 6Fr double lumen Nelaton transurethral catheter was used for infusion and recording of intravesical pressure and a $10 \mathrm{Fr}$ intrarectal balloon catheter filled with $10 \mathrm{ml}$ of saline was used for recording abdominal pressure.

Cough and Valsalva leak point pressure evaluation. Bladders were filled to a volume of $250 \mathrm{ml}$. Before commencing VLPP examination in males the catheter was removed to 
avoid obstructive effects on the urethra. ${ }^{12}$ Patients were placed in an upright position and vesical and abdominal pressures were set at zero, a deviation from the original description of McGuire et $\mathrm{al}^{1}$ that allows comparison with previously reported studies. While standing they were asked to exhibit single coughs until leakage was visualized (CLPP), then they were instructed to strain down slowly as though trying to pass stool and the Valsalva maneuver was repeated several times. We ensured that vesical and abdominal pressures were recording accurately with equal increases in each pressure measurement during these maneuvers, and with subtracted detrusor pressure remaining at 0 . Between each strain a rest period was allowed to avoid muscle fatigue. In the first 2 or 3 strains patients were asked to perform a standard Valsalva maneuver (test A), and in the last 2 or 3 strains patients were asked to strain while inducing a simultaneous relaxation of PFM (test B, modified Valsalva maneuver). During the procedure patients learned in 1 or 2 attempts how to avoid PFM contraction by recognizing and controlling the EMG tracing during the increase in intraabdominal pressure. As soon as leakage occurred an event marker was placed and the lower result was taken for evaluation.

Using accepted criteria female patients were classified according to VLPP values. ${ }^{1,13}$ A VLPP greater than $90 \mathrm{~cm}$ water indicated urethral hypermobility, a VLPP of 90 $\mathrm{cm}$ water or less indicated mild intrinsic sphincter deficiency and a value of $60 \mathrm{~cm}$ water or less indicated severe intrinsic sphincter deficiency. VLPP values obtained during tests A and $B$ were analyzed. Results were reviewed to detect if the classification of urinary incontinence (anatomical or due to intrinsic sphincter deficiency) in females changed by avoiding contraction of PFM during straining.

EMG recording of pelvic floor muscles. During CLPP and VLPP examination muscle activity was recorded by means of surface anal skin electrodes placed at the 3 and 9 o'clock positions. Several parameters were evaluated, including median EMG activity $(\mu \mathrm{V})$ at rest, during CLPP, during VLPP in tests $\mathrm{A}$ and $\mathrm{B}$, increasing EMG activity during test $\mathrm{A}$ (difference between average EMG activity during test $\mathrm{A}$ and at rest), increasing EMG activity during test $B$ (difference between average EMG activity during test $B$ and at rest), and mean duration (seconds) of EMG activity with CLPP during tests $\mathrm{A}$ and $\mathrm{B}$. The amplitude of PFM EMG activity during VLPP (tests A and B) was compared to that during CLPP as a control. All EMG data were collected and analyzed using Eugen I commercial software (New Medical srl, Rome, Italy).

The reliability of the procedures was determined by evaluating the coefficients of variation in a pilot study population. The 11 patients ( 4 males, 7 females) who met elegibility criteria underwent VLPP measurement with EMG recording of PFM activity in tests $\mathrm{A}$ and $\mathrm{B}$ on 2 different days. The coefficients of variation of VLPP values in tests A and B were $4.1 \%$ and $5.0 \%$, respectively. The $\mathrm{cv}_{\mathrm{s}}$ of EMG amplitude in tests A and B were $2.6 \%$ and $3.0 \%$, respectively.

Statistics. The Kolmogorov-Smirnov test was used to assess the distributions of continuous data. The chi-square test, nonparametric Mann-Whitney for unpaired data, and Wilcoxon for paired data were performed using SPSS for Windows release 6.1.3 (SPSS, Inc., Chicago, Illinois). The significance level was set at $\mathrm{p}<0.05$.

\section{RESULTS}

We evaluated 25 females and 14 males with mean age $60.6 \pm 7.5$ years $(58.8 \pm 7.5$ for females and $63.6 \pm 6.6$ for males), and mean duration of urinary incontinence $6.4 \pm 8.6$ years for females and $1.3 \pm 2.4$ for males. No patient complained of fecal or flatus incontinence. Stress urinary incontinence in all male patients was a consequence of radical retropubic prostatectomy. Using the data obtained with cys- tourethrography SUI was classified as type I, type IIA and type III in 8, 11 and 6 female patients, respectively.

PFM activity during VLPP and CLPP measurements (table 1). A simultaneous muscular contraction during VLPP examination was observed in all patients in test A, and in 34 of 39 in test B (in 5 patients EMG activity of PFM during test B was comparable to rest values). There was a significant increase in the amplitude of EMG activity during tests A and B compared to that at rest $(\mathrm{p}<0.0001$ and $\mathrm{p}<0.0001$, respectively). The increasing EMG activity during test $\mathrm{B}$ was significantly reduced compared to that of test $\mathrm{A}$, with 7 (0 to 280) $\mu \mathrm{V}$ vs 16 (0 to 177$) \mu \mathrm{V}, \mathrm{p}<0.01$. The increasing EMG activity during test $\mathrm{A}$ was significantly higher in females than in males, with 19 (0 to 177) $\mu \mathrm{V}$ vs $9(2$ to 39$) \mu \mathrm{V}$, $\mathrm{p}<0.05$. During test $\mathrm{B}$ the increasing EMG activity was significantly reduced compared to test $\mathrm{A}$ in females but not in males, with 8 (0 to 280$) \mu \mathrm{V}$ vs 6.5 (0 to 19$) \mu \mathrm{V}, \mathrm{p}<0.05$. During test A patients with a positive VLPP showed a significantly lower EMG activity than that of continent patients with 145 (139 to 189$) \mu \mathrm{V}$ vs 163 (137 to 317$) \mu \mathrm{V}, \mathrm{p}<0.05$. Conversely, we did not detect any significant difference in EMG activity between continent and incontinent patients in test B. Ultimately, there was no significant difference in the mean duration of EMG activity between tests A and B. A simultaneous muscular contraction was observed in all patients during CLPP, and the median amplitude of PFM EMG activity during CLPP was significantly higher compared to those in tests A and B (table 1).

VLPP and CLPP results (figs. 1 and 2). A positive VLPP was detected in 14 patients ( 7 females and 7 males) during test $A$ and all except 1 also showed urinary leakage in test $B$ (table 2). As a group there was no significant difference in VLPP between tests A and B (table 3 ). Among females only 2 with VLPP values higher than $60 \mathrm{~cm}$ water in test A changed to low values in test $\mathrm{B}$. Among incontinent males VLPP values showed comparable results in tests $\mathrm{A}$ and $\mathrm{B}$. We detected a decrease in maximum abdominal pressure in test B compared to test A, which was significant in females $(\mathrm{p}<0.05)$ but not in males. CLPP values $\left(\mathrm{cm} \mathrm{H}_{2} \mathrm{O}\right)$ were significantly higher compared to VLPP results in tests A and B, with 103 (57 to 204) vs 70 (17 to 148$)$ in test A, and vs 50 (40 to 131$)$ in test B $(\mathrm{p}<0.001$ and $\mathrm{p}<0.001$, respectively).

\section{DISCUSSION}

Valsalva leak point pressure provides a valuable assessment of SUI, the severity of sphincter dysfunction and distinguishes patients with intrinsic sphincter weakness from those affected by anatomical incontinence. Recently there have been efforts to standardize the technique as there is evidence that its variability may influence outcome. ${ }^{2}$ One artifact is a possible increase of VLPP because of voluntary contraction of the external urethral sphincter during the test. ${ }^{3}$ Some patients may contract the sphincter due to irritation by the urethral catheter and mask SUI. ${ }^{14}$

There is no consistent information on the roles of the

TABLE 1. Electromyographic activity of pelvic floor muscles

\begin{tabular}{|c|c|c|c|}
\hline \multirow{2}{*}{\multicolumn{4}{|c|}{$\begin{array}{l}\text { Median } \mu \mathrm{V} \text { amplitude } \\
\quad \text { (range): }\end{array}$}} \\
\hline & & & \\
\hline At rest & $138(132-145)$ & $137(132-145)$ & $138(133-144)$ \\
\hline CLPP & $213(147-352) \dagger$ & $218(152-352)$ & $210(147-345)$ \\
\hline Test A & \multirow{2}{*}{$\begin{array}{l}153(137-317)^{*} \\
144(134-420)^{*}\end{array}$} & \multirow{2}{*}{$\begin{array}{r}145(137-179) \\
143.5(137-159)\end{array}$} & \multirow{2}{*}{$\begin{array}{l}158(138-317) \\
145(134-420)\end{array}$} \\
\hline Test B & & & \\
\hline \multicolumn{4}{|c|}{$\begin{array}{l}\text { Median sec duration } \\
\text { (range): }\end{array}$} \\
\hline CLPP & $(0.5-2)$ & $(0.5-2)$ & $1 \quad(0.5-1.5)$ \\
\hline Test A & (1-9) & $(2-7.5)$ & $4 \quad(1-9)$ \\
\hline Test B & $(2-8)$ & $(2-8)$ & $(2-7)$ \\
\hline
\end{tabular}

* Versus at rest $\mathrm{p}<0.0001$.

$\dagger$ Versus tests $\mathrm{A}$ and $\mathrm{B} \mathrm{p}<0.001$. 

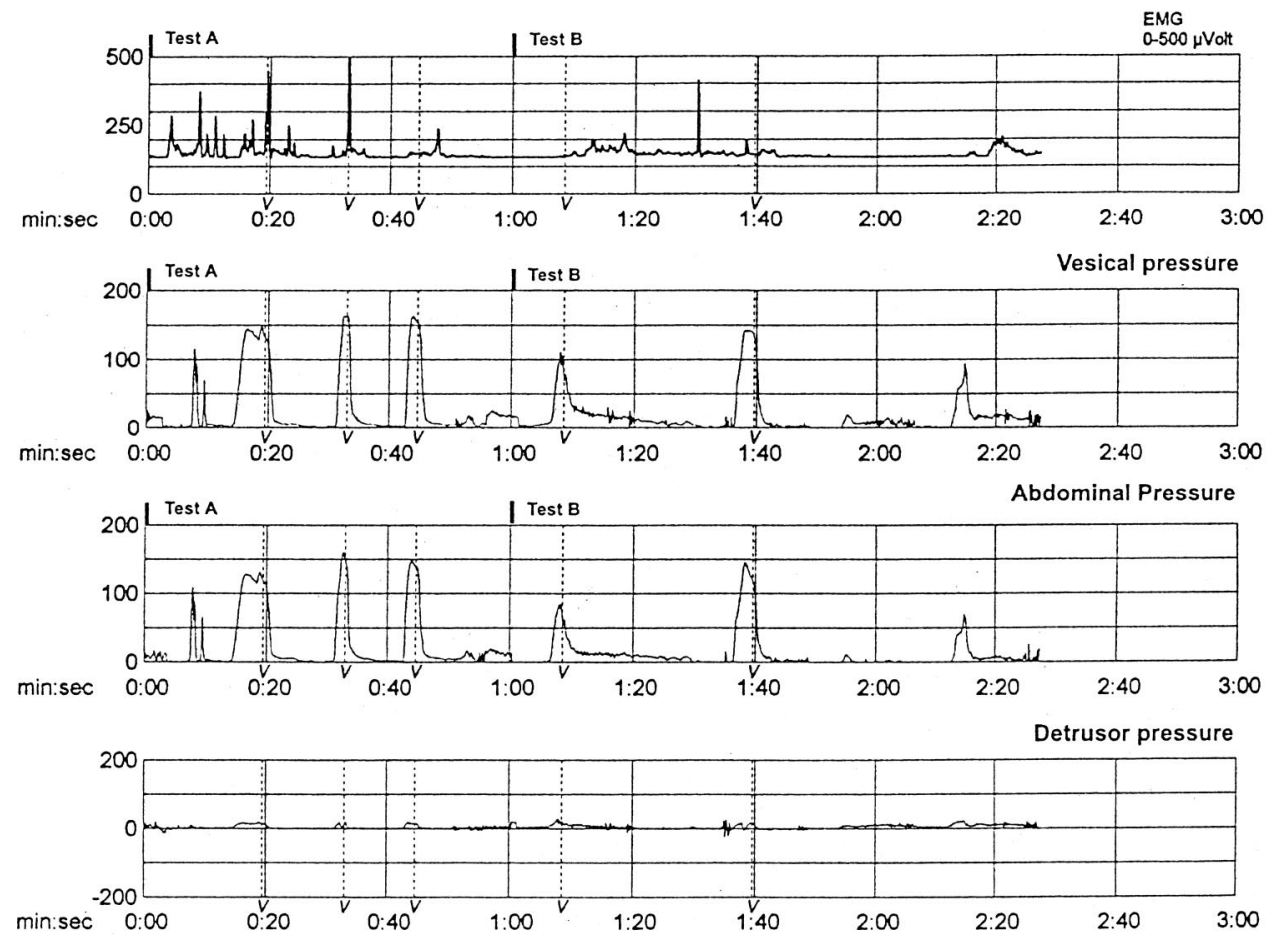

Fig. 1. Electromyographic activity of pelvic floor muscles in female patient during Valsalva leak point pressure measurement with spontaneous strain (test A), or simultaneous relaxation of pelvic floor muscles.

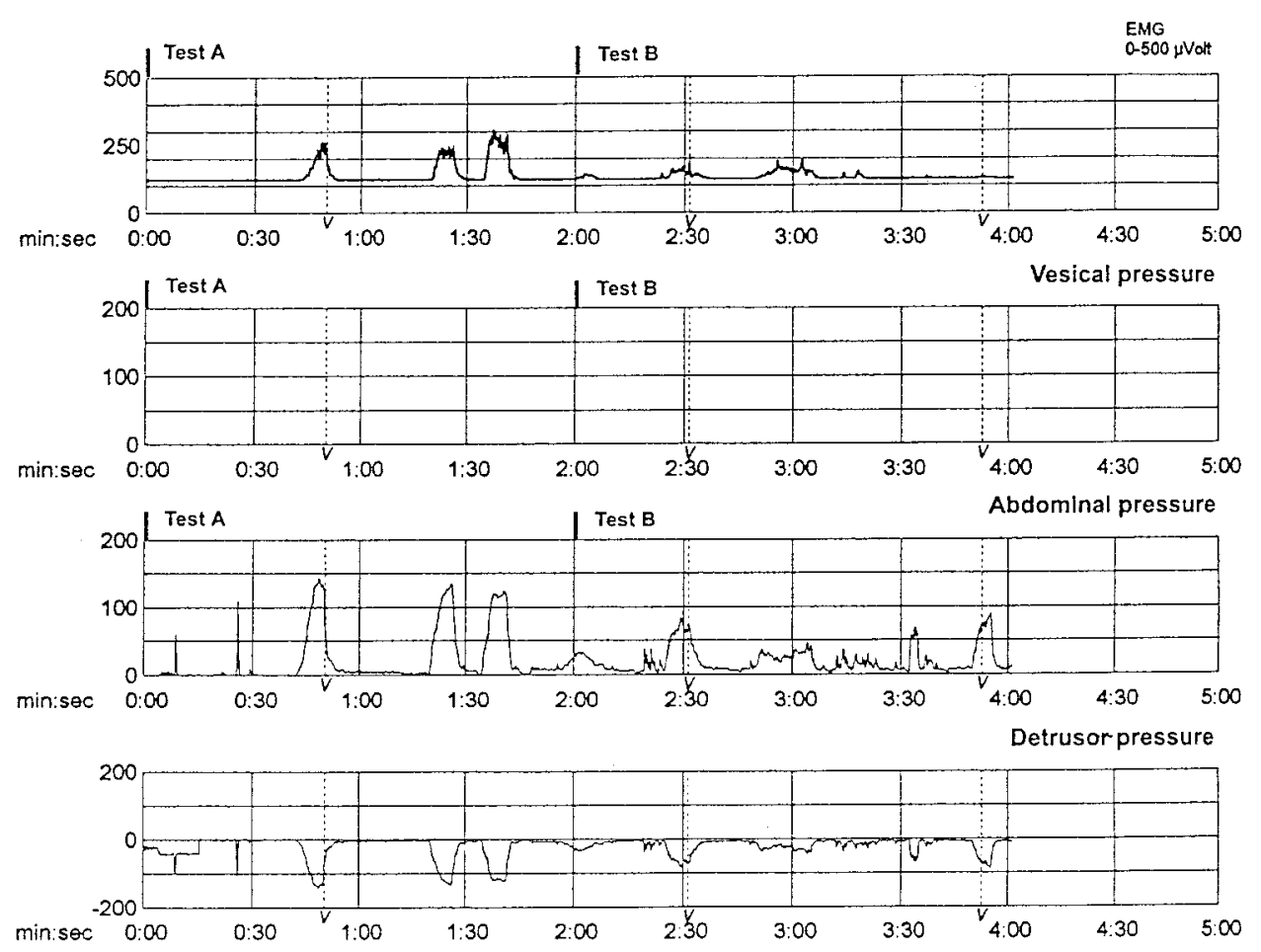

FIG. 2. Electromyographic activity of pelvic floor muscles in male patient during Valsalva leak point pressure measurement with spontaneous strain (test A), or simultaneous relaxation of pelvic floor muscles.

external urethral sphincter and pelvic floor muscles during VLPP measurement. Deindl et al performed simultaneous EMG recordings from the left and right pubococcygeal muscles in 10 continent nulliparous young women and observed a concomitant recruitment of motor units during several maneuvers in both muscles as an appropriate motor pattern for urinary continence during voluntary and reflex activities. ${ }^{15}$ Bo and Stien recorded the EMG activity of the striated ure- thral wall and of PFM in 6 healthy females and reported that the EUS and the PFM react differently during abdominal contraction. ${ }^{16}$ Park et al concluded that an increase in the EUS and PFM activity can be elicited by various stimuli, thereby preventing unwanted urine loss. ${ }^{7}$

Conversely, Shafik observed that the amplitude of action potentials in the EUS increased with coughing but this response was not evoked by slow sustained strain (Valsalva), so 
TABLE 2. Valsalva leak point pressure values

\begin{tabular}{ccc}
\hline Pt No.-Sex & $\begin{array}{c}\text { Test A } \\
\left(\mathrm{cm} \mathrm{H}_{2} \mathrm{O}\right)\end{array}$ & $\begin{array}{c}\text { Test B } \\
\text { (cm H}\end{array}$ \\
\hline 1-F & 21 & 40 \\
$2-\mathrm{M}$ & 74 & 75 \\
$3-\mathrm{F}$ & - & 75 \\
4-F & 70 & 70 \\
$5-\mathrm{F}$ & 40 & 40 \\
6-M & 75 & 75 \\
$7-\mathrm{M}$ & 17 & 40 \\
8-M & 55 & 50 \\
9-F & 96 & - \\
$10-\mathrm{M}$ & 115 & 115 \\
$11-\mathrm{F}$ & 131 & 42 \\
$12-\mathrm{F}$ & 83 & 125 \\
$13-\mathrm{M}$ & 148 & 45 \\
$14-\mathrm{M}$ & 47 & 47 \\
$15-\mathrm{F}$ & 67 & \\
\hline
\end{tabular}

TABLE 3. Maximum abdominal pressure and Valsalva leak point pressure values

\begin{tabular}{|c|c|c|c|c|}
\hline \multirow[b]{3}{*}{ Overall } & \multicolumn{2}{|c|}{$\begin{array}{c}\text { Median Max } \mathrm{Cm}_{2} \mathrm{O} \\
\text { Abdominal Pressure (range) }\end{array}$} & \multicolumn{2}{|c|}{$\begin{array}{l}\text { Median } \mathrm{Cm} \mathrm{H}_{2} \mathrm{O} \text { Valsalva } \\
\text { Leak Point Pressure (range) }\end{array}$} \\
\hline & Test A & Test B & Test A & Test B \\
\hline & $95 \quad(17-155)^{*}$ & $75 \quad(20-147)$ & $(17-148) \ddagger$ & $50 \quad(40-131)$ \\
\hline Males & $107.5(17-150)$ & $87.5(40-140)$ & $74 \quad(17-148)$ & $50 \quad(40-125)$ \\
\hline Females & $90 \quad(21-155)$ & $75 \quad(20-147) \dagger$ & $68.5(21-131)$ & $58.5(40-131)$ \\
\hline
\end{tabular}

that straining during Valsalva is performed under voluntary control during defecation or micturition and it is accompanied by relaxation of the external urethral sphincter and the opening of the vesical neck. ${ }^{6}$ Petrou and Kollmorgen ${ }^{4}$ and Peschers et $a^{5}$ explained that VLPP values are higher during coughing than during Valsalva without directly recording the EMG activity during VLPP examination. Finally, Abrams states that one of the most important assumptions is that there is no PFM relaxation or contraction during the test. ${ }^{17}$

Comparison with these previous studies is difficult because of different selection of patients and different study protocols applied. The current study is a preliminary investigation describing pelvic floor muscle activity during VLPP measurements and seeks to determine whether an increase of this activity affects VLPP results. Although it can be argued that the activity in the rectal sphincter is different from that in the EUS as measured with needle electrodes, difficulties in the placement of the needles and patient discomfort led us to use surface EMG recordings in which the signal source difficulties are primarily of technical origin and usually can be avoided.18 Furthermore, in an intact nervous system, the recorded PFM activity is also indicative of EUS activity because of their common innervation arising primarily from sacral roots $\mathrm{S} 2$ and $\mathrm{S} 3 .{ }^{19,20}$ Our data indicate that during VLPP examination there is a simultaneous contraction of PFM, as demonstrated by the significant increase of EMG activity during tests $\mathrm{A}$ and $\mathrm{B}$. After asking the patients to avoid PFM contraction during Valsalva (test B), an increase in EMG activity of PFM persists in the majority of patients but is significantly reduced compared to that of test A, possibly because of either an involuntary guarding reflex and/or a voluntary phenomenon. ${ }^{7}$ Park et al describe the guarding reflex as involuntary at low bladder volume and becoming a conscious phenomenon when the sensory threshold of bladder fullness is reached. ${ }^{7}$ Probably the conditions imposed by the tests induced patients to voluntarily augment the guarding reflex to prevent unwanted urine loss. Because patients tried to avoid PFM contraction during Valsalva in test B, the residual muscular activity could be due either to a reflex condition or to incomplete PFM relaxation.
In the current study all patients underwent CLPP and VLPP examination. Although all patients had a positive CLPP, a positive VLPP was obtained in only $36 \%$ of patients, consistent with reports that about $40 \%$ to $50 \%$ of patients with a positive CLPP do not leak while performing a Valsalva maneuver. ${ }^{5,21}$ The significantly higher EMG activity during CLPP measurement indicates a different reaction of the pelvic floor to the higher increase in intra-abdominal pressure during coughing. The significantly lower EMG activity observed in incontinent patients during a standard Valsalva maneuver may indicate a major weakness of periurethral and pelvic floor musculature causing very obvious urinary incontinence. ${ }^{22}$ The augmented activity of PFM did not significantly increase VLPP values in our patients and in females the VLPP classification of SUI did not change significantly, which is in contrast to studies by Blaivas $^{3}$ and Maniam and Goldman ${ }^{14}$ who hypothesized that voluntary contraction of the striated sphincter increases the leak point pressure.

Finally, the lower EMG activity of PFM in males compared to that of females may be due to the lack of the irritation by the urethral catheter. Another explanation is that females have more effective voluntary control of the sphincter and pelvic muscles as an acquired defense against urinary incontinence, but the small number of males in the current study does not permit definitive conclusions about different PFM behavior between the sexes.

\section{CONCLUSIONS}

Voluntary contraction of PFM is common in patients performing Valsalva leak point examination. It does not significantly alter VLPP results and may indicate an augmented guarding reflex against unwanted urinary incontinence. Male patients performing VLPP examination without the presence of the urethral catheter show decreased contractions of PFM, possibly because of the lack of an irritant factor to the urethra or because of a different behavior pattern as compared to females. Further investigations are required in healthy males and females to confirm the hypothesis that voluntary control differs between the sexes.

\section{REFERENCES}

1. McGuire, E. J., Fitzpatrick, C. C., Wan, J., Bloom, D., Sanvordenker, J., Ritchey, M. and Gormley, E. A.: Clinical assessment of urethral sphincter function. J Urol, 150: 1452, 1993

2. Faerber, G. J. and Vashi, A. R.: Variations in Valsalva leak point pressure with increasing vesical volume. J Urol, 159: 1909, 1998

3. Blaivas, J. G.: Editorial: Incontinence. J Urol, 150: 1455, 1993

4. Petrou, S. P. and Kollmorgen, T. A.: Valsalva leak point pressure and bladder volume. Neurourol Urodyn, 17: 3, 1998

5. Peschers, U. M., Jundt, K. and Dimpfl, T.: Differences between cough and Valsalva leak-point pressure in stress incontinent women. Neurourol Urodyn, 19: 677, 2000

6. Shafik, A.: Straining urethral reflex: description of a reflex and its clinical significance. Preliminary report. Acta Anat, 140: 104, 1991

7. Park, J. M., Bloom, D. A. and McGuire, E. J.: The guarding reflex revisited. Br J Urol, 80: 940, 1997

8. Abrams, P., Cardozo, L., Fall, M., Griffiths, D., Rosier, P., Ulmsten, U. et al: The standardisation of terminology of lower urinary tract function: report from the Standardisation Subcommittee of the International Continence Society. Neurourol Urodyn, 21: 167, 2002

9. McGuire, E. J., Cespedes, R. D. and O'Connell, H. E.: Leak-point pressures. Urol Clin North Am, 23: 253, 1996

10. Blaivas, J. G. and Olsson, C. A.: Stress incontinence: classification and surgical approach. J Urol, 139: 727, 1988

11. Schafer, W., Abrams, P., Liao, L., Mattiasson, A., Pesce, F., Spangberg, A. et al: Good urodynamic practices: uroflowmetry, filling cystometry, and pressure-flow studies. Neurourol Urodyn, 21: 261, 2002 
12. Flood, H. D. and Liu, J.: The effect of the urethral catheter on leak point pressure determination in patients being assessed for urethral reconstruction. Presented at annual meeting of Urodynamics Society, Las Vegas, Nevada, April 23, 1995

13. Nitti, V. W. and Combs, A. J.: Correlation of Valsalva leak point pressure with subjective degree of stress urinary incontinence in women. J Urol, 155: 281, 1996

14. Maniam, P. and Goldman, H. B.: Removal of transurethral catheter during urodynamics may unmask stress urinary incontinence. J Urol, 167: 2080, 2002

15. Deindl, F. M., Vodusek, D. B., Hesse, U. and Schussler, B.: Activity patterns of pubococcygeal muscles in nulliparous continent women. Br J Urol, 72: 46, 1993

16. Bo, K. and Stien, R.: Needle EMG registration of striated urethral wall and pelvic floor muscle activity patterns during cough, Valsalva, abdominal, hip adductor, and gluteal muscle contractions in nulliparous healthy females. Neurourol Urodyn, 13: 35, 1994
17. Abrams, P.: Urodynamic techniques. In: Urodynamics, 2nd ed. New York: Springer Verlag, chapt. 3, p. 113, 1997

18. O’Donnell, P., Beck, C., Doyle, R. and Eubanks, C.: Surface electrodes in perineal electromyography. Urology, 32: 375, 1988

19. Juenemann, K.-P., Lue, T. F., Schmidt, R. A. and Tanagho, E. A.: Clinical significance of sacral and pudendal nerve anatomy. J Urol, 139: 74, 1988

20. Borirakchanyavat, S., Aboseif, S. R., Carroll, P. R., Tanagho, E. A. and Lue, T. F.: Continence mechanism of the isolated female urethra: an anatomical study of the intrapelvic somatic nerves. J Urol, 158: 822, 1997

21. Haab, F., Ciofu, C., Pedron, P., Lukacs, B., Doublet, J. D., Gattegno, B. et al: Feasibility of "Valsalva Leak Point Pressure”. Prospective study. Prog Urol, 7: 611, 1997

22. Gunnarsson, M. and Mattiasson, A.: Circumvaginal surface electromyography in women with urinary incontinence and in healthy volunteers. Scand J Urol Nephrol Suppl, 157: 89, 1994 